\title{
Stability of methacholine chloride solutions under different storage conditions over a 9 month period
}

\author{
R.D. Hayes*, J.R. Beach**, D.M. Rutherford+, M.R. Sim*
}

Stability of methacholine chloride solutions under different storage conditions over a 9 month period. R.D. Hayes, J.R. Beach, D.M. Rutherford, M.R. Sim. CERS Journals Ltd 1998.

ABSTRACT: Methacholine chloride solutions, routinely used for testing bronchial hyperreactivity, have been shown to degrade over time. The data published addressing the optimal conditions for methacholine chloride storage are conflicting and incomplete. This study investigated the effects of a variety of conditions on the stability of methacholine chloride.

Methacholine chloride, dissolved in phosphate buffered saline (PBS) or sodium chloride $(\mathrm{NaCl})$ at 50 and $0.39 \mathrm{~g} \cdot \mathrm{L}^{-1}$, was subjected to various light and temperature conditions for 9 months. Methacholine chloride degradation was determined by high performance liquid chromatography, and all solutions underwent bacterial and $\mathbf{p H}$ testing.

By 9 months, all $50 \mathrm{~g} \cdot \mathrm{L}^{-1}$ solutions of methacholine chloride had degraded by $6.5 \pm 0.8 \%$. All $0.39 \mathrm{~g} \cdot \mathrm{L}^{-1}$ solutions in $\mathrm{NaCl}$ had degraded by $11.0 \pm 0.3 \%$. The $0.39 \mathrm{~g} \cdot \mathrm{L}^{-1}$ solutions in PBS which had been frozen, refrigerated or stored at room temperature had degraded by $8.0 \%, 16.0 \pm 0.3 \%$ and $63.8 \pm 0.5 \%$, respectively. The pH of methacholine chloride was 7.2 in PBS at $0.39 \mathrm{~g} \cdot \mathrm{L}^{-1}, 5.8$ in $\mathbf{P B S}$ at $50 \mathrm{~g} \cdot \mathrm{L}^{-1}, 3.9$ in $\mathrm{NaCl}$ at 0.39 and 2.7 in $\mathrm{NaCl}$ at $50 \mathrm{~g} \cdot \mathrm{L}^{-1}$. Bacterial contamination was minimal.

The results of this study demonstrate that methacholine chloride is more stable at the higher concentration. However, the $\mathrm{pH}$ of the more concentrated solutions of methacholine chloride in sodium chloride could cause bronchoconstriction in some subjects. We therefore recommend storing methacholine chloride at $50 \mathrm{~g} \cdot \mathrm{L}^{-1}$ in phosphate-buffered saline.

Eur Respir J 1998; 11: 946-948.
*Dept of Epidemiology and Preventive Medicine, Monash Medical School, Melbourne, Australia. **Institute of Occupational Health, Birmingham, UK. +Dept of Clinical Biochemistry, Alfred Hospital, Melbourne, Australia.

Correspondence: R.D. Hayes

Dept of Epidemiology and Preventive Medicine

Monash Medical School

Alfred Hospital

Prahran

3181

Australia

Keywords: High performance liquid chromatography

methacholine

$\mathrm{pH}$

stability

storage conditions

Received: March 241997

Accepted after revision October 211997

This study was supported by a grant from Alcoa of Australia
Methacholine chloride, a synthetic analogue of the neurotransmitter acetylcholine, is widely used in respiratory function laboratories and epidemiological field studies, with solutions of methacholine chloride being nebulized and then inhaled as a nonspecific challenge test for bronchial hyperreactivity [1]. The accuracy of the methacholine chloride inhalation challenge test is dependent on the use of precise concentrations of methacholine chloride. However methacholine chloride in solution has been shown to degrade over time [2-5]. To avoid both compromising the accuracy of the methacholine chloride inhalation challenge test and unnecessarily discarding costly solutions, further information on the stability of methacholine chloride is needed.

The data published concerning the maximum time and optimal conditions for the storage of methacholine chloride solutions are conflicting. The Merck manual reports that, after only 2 weeks, even refrigerated solutions of methacholine chloride will lose sufficient potency to warrant them being discarded [2]. However, various other researchers have reported shelf lives of methacholine chloride dissolved in $0.9 \%$ sodium chloride $(\mathrm{NaCl})$ ranging 4-10 months for refrigerated solutions [3, 4], and 4-6 months for solutions stored at room temperature [3-5]. Furthermore, both the concentrations of methacholine chloride solutions and the assays used to determine the level of methacholine chloride degradation differ markedly between studies [3-7]. These differences have hampered attempts at making direct comparisons between the findings.

In practice, methacholine chloride dissolved either in $\mathrm{NaCl}$ or phosphate-buffered saline (PBS) is used for inhalation challenges [1]. However, almost all methacholine chloride stability research has focused on methacholine chloride dissolved in $\mathrm{NaCl}$. One report, which investigated the effects of both solvents over a 3 month period, found preliminary evidence that methacholine chloride may be more chemically unstable when dissolved in PBS [1, 8]. It has also been suggested that bacterial contamination may enhance the degradation of methacholine chloride solutions [1]. This, however, remains to be conclusively demonstrated.

The available literature is inconsistent and, since some of the previously reported shelf lives were only estimations made by extrapolating data collected over a shorter period of time [3], we elected to perform our own study over an extended duration. To clarify the issue of acceptable storage conditions, we investigated the effects of light, temperature, concentration, solvent type and bacterial contamination on the rate of methacholine chloride degradation. 


\section{Materials and methods}

\section{Study design}

We chose to investigate methacholine chloride solutions at concentrations of 50 and $0.39 \mathrm{~g} \cdot \mathrm{L}^{-1}$, dissolved either in PBS or $\mathrm{NaCl}$. These concentrations were the maximum and minimum doses used in our bronchial provocation test protocol, which was derived from the protocol used in the European Community Respiratory Health Survey [9]. Each of the four combinations of methacholine chloride concentration and solvent was stored in one of the following environments for a period of 9 months: room temperature and light; room temperature and darkness; or refrigeration and darkness. At the beginning of the experiment, all solutions of methacholine chloride were freshly prepared from powder under sterile conditions, stored in rubber-sealed glass vials and tested for bacterial content. Every 4 weeks, $1 \mathrm{~mL}$ aliquots were extracted from each vial using a sterile syringe and needle and assayed by high performance liquid chromatography (HPLC). In addition to the vials of methacholine chloride, which were assayed monthly, replicate vials were stored unopened under identical conditions for the duration of the experiment, as a control for bacterial contamination. Two vials containing methacholine chloride in PBS, one at each concentration, were stored at $-20^{\circ} \mathrm{C}$ for the duration of the experiment. At the end of the experiment, the contents of each vial were tested for bacterial contamination, assayed by HPLC, and the $\mathrm{pH}$ of each was measured.

\section{Methods}

Methacholine chloride, in powder form, was obtained from ACIC Inc. (Ontario, Canada) and stored in its original container in a vacuum desiccator at $4^{\circ} \mathrm{C}$. Methacholine chloride was dissolved either in $0.9 \%$ sterile intravenous saline infusion (Baxter Healthcare Pty Ltd, NSW, Australia) or PBS consisting of $32.8 \mathrm{~g} \mathrm{NaCl}$ (David Craig and Co., Rocklea, Australia), 11.385 g sodium orthophosphate. $12 \mathrm{H}_{2} \mathrm{O}$ (Fluka via FSE, NSW, Australia), $1.25 \mathrm{~g}$ sodium dihydrogen phosphate. $2 \mathrm{H}_{2} \mathrm{O}$ (Fluka via FSE, NSW, Australia), and made up to $4 \mathrm{~L}$ in water for injections (Baxter Healthcare Pty Ltd, NSW, Australia). Aliquots $(25 \mathrm{~mL})$ of these solutions were dispensed into rubbersealed glass vials. All methacholine chloride solutions were made up under a laminar flow hood using standard sterile techniques.

Each time a vial was sampled, the following technique was used: firstly, the outside of the rubber seal on each vial was disinfected with an alcohol swab; and then, using a sterile $2.5 \mathrm{~mL}$ syringe and $21 \mathrm{G} \times 1.25$ " needle, $1 \mathrm{~mL}$ of air was injected into the vial and a $1 \mathrm{~mL}$ aliquot of methacholine chloride solution was drawn.

At the end of the 9 month period, bacterial contamination was assessed by plating out $0.5 \mathrm{~mL}$ aliquots from all vials onto Colombia blood agar containing $5 \%$ sterile defribrinated horse blood cells in $20 \mathrm{~mL}$ plastic Petri dishes, and incubating these for $48 \mathrm{~h}$ at $35^{\circ} \mathrm{C}$. This procedure was performed under a laminar flow hood using standard sterile techniques. These aliquots were taken prior to the final assaying of all samples by HPLC, so that those vials which had not undergone monthly sampling would still be in an untouched state. The types of bacteria present were identified by colonial morphology.

\section{Analysis}

The methodology for the HPLC assay used in this study was a modification of the method described in detail by Woodman et al. [6]. A prepacked $3.9 \times 150 \mathrm{~mm}$ Waters Symmetry C18, $5 \mu \mathrm{m}$ column (Lot No. T52071 R21, Batch No. 113) was used with a mobile phase of $20 \%$ acetonitrile (Mallinckrodt, ChromAR HPLC grade, Biolab Scientific Pty Ltd, Victoria, Australia) and 80\% 1-heptane sulphonic acid sodium salt (HiPerSolv for HPLC, BDH Laboratory Supplies, Poole, UK) at $0.01 \mathrm{M}$ in deionized water. On this column, methacholine chloride had a retention time of $3.25 \mathrm{~min}$. Methacholine chloride solutions, at concentrations of 50 and $0.39 \mathrm{~g} \cdot \mathrm{L}^{-1}$ were diluted $1 / 50$ and $1 / 10$, respectively, with deionized water prior to being assayed.

Solutions containing only $\mathrm{NaCl}$ or PBS did not display HPLC peaks with the same retention time as methacholine chloride. The concentration of methacholine chloride was determined by comparing the HPLC peak heights of methacholine chloride in the study samples with those from standard solutions of methacholine chloride, which were freshly prepared just prior to the analysis. The $\mathrm{pH}$ of methacholine chloride samples was measured using a Beckman $\Phi 44 \mathrm{pH}$ meter (Beckman, Melbourne, Australia)

\section{Results}

Figure 1 shows the results for the $0.39 \mathrm{~g} \cdot \mathrm{L}^{-1}$ solutions of methacholine chloride over the 9 months under each of the test conditions. At the end of 9 months, solutions of $0.39 \mathrm{~g} \cdot \mathrm{L}^{-1}$ methacholine chloride in PBS stored at room temperature had degraded by as much as $63.8 \pm 0.5 \%$,

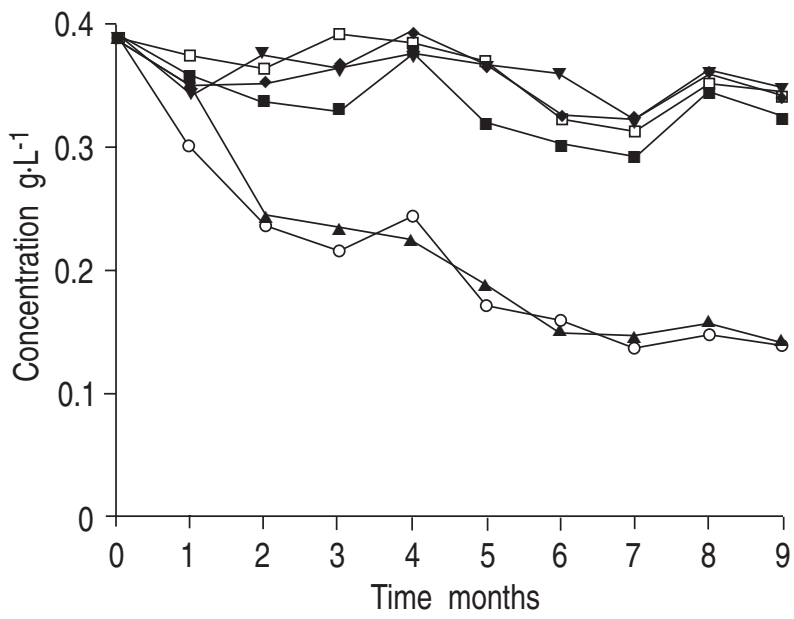

Fig. 1. - Changes in the concentration of methacholine chloride solutions, dissolved either in phosphate-buffered saline (PBS) or sodium chloride $(\mathrm{NaCl})$ at $0.39 \mathrm{~g} \cdot \mathrm{L}^{-1}$ and subjected to various conditions of light and temperature for 9 months. Values are the mean of three measurements. $\square-: 9 \% \mathrm{NaCl}$, light, room temperature (RT); —— : PBS, light,

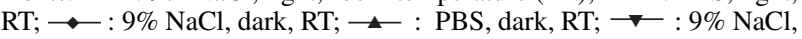
dark, refrigeration; $\rightarrow-$ : PBS, dark, refrigeration. 
whereas similar solutions which had been refrigerated or frozen had degraded by only $16.0 \pm 0.3 \%$ and $8 \%$ (data not shown), respectively. Exposure to light had no effect on the degradation rate of these solutions. All $0.39 \mathrm{~g} \cdot \mathrm{L}^{-1}$ methacholine chloride solutions in $\mathrm{NaCl}$ displayed a mean degradation of $11.0 \pm 0.3 \%$ at the end of 9 months, regardless of whether they were stored at room temperature, refrigerated, or exposed to light.

The $50 \mathrm{~g} \cdot \mathrm{L}^{-1}$ solutions of methacholine chloride displayed a mean degradation of $6.5 \pm 0.8 \%$ at the end of 9 months. The rate of degradation was not affected by light, temperature or the type of solvent used.

Three of the 26 vials tested displayed a positive result for bacterial contamination. These vials were: $0.39 \mathrm{~g} \cdot \mathrm{L}^{-1}$ methacholine chloride in PBS stored at $-20^{\circ} \mathrm{C}$ in the dark and unopened, $0.39 \mathrm{~g} \cdot \mathrm{L}^{-1}$ methacholine chloride in PBS stored at room temperature in the dark and unopened; and $0.39 \mathrm{~g} \cdot \mathrm{L}^{-1}$ methacholine chloride in PBS stored at room temperature in the light and sampled during the experiment. In each of these cases, the contamination was extremely minor comprising a single colony of coagulase-negative Staphylococcus (a common skin commensal). There were no significant differences between the levels of methacholine chloride remaining in vials which had undergone monthly sampling and the replicate vials which had remained untouched.

Methacholine chloride in PBS displayed a pH of 7.2 at $0.39 \mathrm{~g} \cdot \mathrm{L}^{-1}$ and 5.8 at $50 \mathrm{~g} \cdot \mathrm{L}^{-1}$. When dissolved in $\mathrm{NaCl}$, methacholine chloride displayed a $\mathrm{pH}$ of 3.9 at $0.39 \mathrm{~g} \cdot \mathrm{L}^{-1}$ and 2.7 at $50 \mathrm{~g} \cdot \mathrm{L}^{-1}$.

\section{Discussion}

Our findings clearly demonstrate that manipulating the storage conditions of methacholine chloride solutions can have a profound effect on the rate of degradation. These data reveal that temperature, methacholine chloride concentration and the type of solvent in combination influence the degradation rate of stored solutions of methacholine chloride, whilst exposure to light has no apparent effect.

There are significant advantages in storing methacholine chloride at a high concentration. The most concentrated solutions of methacholine chloride $\left(50 \mathrm{~g} \cdot \mathrm{L}^{-1}\right)$ displayed the lowest level of degradation of all solutions in this study. At high concentrations, methacholine chloride can be dissolved either in PBS or $\mathrm{NaCl}$ without adversely affecting its stability, and refrigeration is not required to prolong the shelf life of these solutions.

At low concentrations, the stability of solutions of methacholine chloride is influenced both by temperature and the type of solvent used. When dissolved in $\mathrm{NaCl}$, weak concentrations of methacholine chloride $\left(0.39 \mathrm{~g} \cdot \mathrm{L}^{-1}\right)$ degrade at the same slow rate irrespective of whether they are refrigerated or stored at room temperature. However, when dissolved in PBS, the degradation rates of these solutions are dramatically increased by raising the storage temperature. It is, therefore, advisable to refrigerate or freeze low concentrations of methacholine chloride if they have been dissolved in PBS.

Whilst it has been suggested that bacterial contamination may accelerate the degradation of methacholine chloride solutions [1], our results indicate that this should not be a problem if aseptic techniques are used when taking samples. In the majority of cases, bacterial contamination did not ensue as a result of taking multiple samples from the vials in this study. The contamination which did occur is more likely to have been introduced during the final bacterial assay than as a result of taking monthly samples, since two of the three apparently contaminated vials had remained sealed for the duration of the experiment. However, it would be prudent to periodically assay methacholine chloride solutions for bacterial contamination if they are being stored for long periods, especially if solutions are being stored at room temperature.

Prima facie, it is preferable to dissolve methacholine chloride in $\mathrm{NaCl}$, since the less concentrated solutions were more stable when this solvent was used. However, $\mathrm{NaCl}$ does not have the $\mathrm{pH}$ buffering capacity of PBS. Thus, the more concentrated solutions of methacholine chloride in $\mathrm{NaCl}$ reached a $\mathrm{pH}$ as low as 2.7. In some subjects, this may be sufficient to cause bronchoconstriction by virtue of the $\mathrm{pH}$ alone [10]. For this reason, there is a case for using PBS as a solvent for methacholine chloride in methacholine challenge tests. We therefore recommend that methacholine chloride solutions be stored in PBS, rather than normal saline, and at a concentration of around $50 \mathrm{~g} \cdot \mathrm{L}^{-1}$. Such solutions can be stored with or without refrigeration, in the light or dark, for up to 9 months, without significant degradation.

Acknowledgements: The authors wish to thank M. Abramson for his helpful comments, J. Cassidy for performing the microbiological assay and K. McIlwaine for assisting with a number of the HPLC assays.

\section{References}

1. Sterk PJ, Fabbri LM, Quanjer PH, et al. Airway responsiveness: standardized challenge testing with pharmacological, physical and sensitizing stimuli in adults. Eur Respir J 1993; 6: Suppl. 16, 53-83.

2. Budavari S, ed. In: The Merck index. 12th Edn. Rahway, USA, Merck. 1996; pp. 1014-1015.

3. Macdonald NC, Whitmore CK, Makoid MC, Cobby J. Stability of methacholine chloride in bronchial provocation test solutions. Am J Hosp Pharm 1981; 38: 868-871.

4. Pratter MR, Woodman TF, Irwin RS, Johnson B. Stability of stored methacholine chloride solutions. Am Rev Respir Dis 1982; 126: 717-719.

5. Tipton WR, Ledoux RA. Functional shelf life of methacholine and atropine methylnitrate solutions. Ann Allergy 1986; 56: 117-119.

6. Woodman TF, Johnson B, Marwaha RK. Determination of methacholine chloride by ion-pair high-pressure liquid chromatography. J Liquid Chrom 1982; 5(7): 1341-1348.

7. Abramson M. Bronchial reactivity in aluminium smelter workers. PhD thesis, University of Newcastle, 1989; 7375,86 and 94.

8. Rosenfeld J, Juniper EF, Hargreave FE. Gas chromatographic determination of methylcholine chloride in pharmaceutical preparations. J Chromatogr 1984; 287: 433 437.

9. Burney PGJ, Luczynska C, Chinn S, Jarvis D. European study protocols. The European Community Respiratory Health Survey. Eur Respir J 1994; 7: 954-960.

10. Cockcroft BW, Berschlid BA. Effect of $\mathrm{pH}$ on bronchial response to histamine. Thorax 1982; 87: 133-136. 